\title{
Correction to: Clinical and radiographic predictors of failed hip arthroscopy in the management of dysplasia: a systematic review and proposal for classification
}

\author{
Ajay Shah ${ }^{1} \cdot$ Jeffrey Kay ${ }^{2} \cdot$ Muzammil Memon ${ }^{2} \cdot$ Nicole Simunovic $^{2} \cdot$ Soshi Uchida ${ }^{3} \cdot$ Nicolas Bonin $^{4}$. \\ Olufemi R. Ayeni ${ }^{2,5,6}$ (D)
}

Published online: 22 April 2019

(c) European Society of Sports Traumatology, Knee Surgery, Arthroscopy (ESSKA) 2019

\section{Correction to: \\ Knee Surgery, Sports Traumatology, Arthroscopy \\ https://doi.org/10.1007/s00167-019-05416-3}

Unfortunately, the author name was incorrectly published in the original publication as Sochi Uchida insted of Soshi Uchida. The author name is corrected here by this Erratum. The original article has been corrected.

Publisher's Note Springer Nature remains neutral with regard to jurisdictional claims in published maps and institutional affiliations.

The original article can be found online at https://doi.org/10.1007/ s00167-019-05416-3.

Olufemi R. Ayeni

ayenif@mcmaster.ca

Ajay Shah

ajay.shah.1996@gmail.com

Jeffrey Kay

jeffrey.kay@medportal.ca

Muzammil Memon

muzammil.memon@medportal.ca

Nicole Simunovic

simunovic@mcmaster.ca

Soshi Uchida

soushi@med.uoeh-u.ac.jp

Nicolas Bonin

n.bonin@gmail.com
1 Michael G. DeGroote School of Medicine, McMaster University, Hamilton, ON, Canada

2 Division of Orthopaedic Surgery, Department of Surgery, McMaster University, Hamilton, ON, Canada

3 Department of Orthopaedic Surgery and Sports Medicine, Wakamatsu Hospital of University of Occupational and Environmental Health, Kitakyushu, Japan

4 Department of Hip Surgery, Lyon Ortho Clinic, Clinique de la Sauvegarde, 25B Avenue des Sources, 69009 Lyon, France

5 Department of Health Research Methods, Evidence, and Impact, McMaster University, Hamilton, ON, Canada

6 McMaster University Medical Centre, 1200 Main St W, Room 4E15, Hamilton, ON L8N 3Z5, Canada 